\title{
Foundations of mathematics play the baseline for data exploring, forecasting and analyzing of risks to get an economic decision
}

\author{
Gazi Farok $^{1,2 \star}$ and Soheil Homayouni ${ }^{1,3}$ \\ ${ }^{1}$ Ryerson University, Toronto, Canada. \\ 2York University, Toronto, Canada \\ ${ }^{3}$ University of Toronto, Canada.
}

Accepted 23 June, 2018

\begin{abstract}
'Foundations of mathematics' are the studies of philosophical and logical concepts. Functional like statistics, optimization, probability, queuing theory, control, game theory, modeling and operations research --- a field devoted entirely to the application of mathematics in decision making. The advances in and applications of the mathematical sciences in decision making have become drivers of innovation as new systems and methodologies to an aspect where, today of concerning the nature of 'mathematics' drives innovation as well as career.
\end{abstract}

Keywords: Mathematics, decision, economic, foundations, forecasting.

*Corresponding author. E-mail: gazi.farok@yahoo.com.

\section{INTRODUCTION}

Mathematical models underlie computer programs that support decision making, while bringing order and understanding to the overwhelming flow of computing data base. It defines equations, theories and their 'models' giving a meaning to equations, definitions, proofs, algorithms, applications of concerning the nature of mathematics etc (Lambek, 2007). Model serves to evaluate and improve the quality of information in the face of uncertainty, to present and clarify options, to model available alternatives and their consequences, and even to control the smaller decisions necessary to reach a larger goal (Nagele, 2003): a) To use a particular error calculation for judging the risk uncertainty of relevant data, b) To compare the accuracy of different decision, c) To measure the opportunity of a particular risk factors for an optimal level of economic decision, d) To find an understanding and interpreting the management decision for future planning process.

\section{DATA COLLECTION AND FORECASTING TECHNIQUES}

Usually data contains facts and statistics for references and analysis. The process of finding a mathematical model that best fits the data is a useful tool for economic analysis (Mendenhall and Sincich, 2012). Data might be reliable and accurate, relevant, consistent and timely to get an economic concept. Trend data, random data can be used to obtain a perfect decision. The overriding consideration in choosing a risk analysis method is that the results must facilitate the decision-making process of the organization's managers. Considerations, related to types of decision factors: Level of detail: micro or macro, Time frame: short-term or long-term, qualitative or quantitative, form of forecast: point, interval, density etc. All decision making procedures involve the assumption that the conditions that generated past relations and data 
are indistinguishable from the conditions of future. Data rationalizes the shifting of information and the balancing of alternatives inherent in any decision (John and Dean, 2008).

\section{METHODOLOGIES}

There are two commonly used techniques: event-oriented and project risk oriented analysis. This process occurs on a strategic level and the operational level.

\section{Event oriented}

Theories for deviation and percentage of error: Empirical research implies that the forecast accuracy of simple method is often as good as that of complex or statistically sophisticated analysis (Makridakis and Hibon, 2000). These methods must be evaluated in terms of its reliability and applicability to the problem at hand, its cost effectiveness and accuracy compared with competing techniques and its acceptance by management. Event oriented decision making procedures: Problem formulation and data collection, Data manipulation and cleaning, Model building and evaluation, Model implementation (the actual forecast). Forecast evaluation. Management ability and common sense must be involved in the decision making process. This should not be a monitor of an automatic decision making device. Questions should be asked on several aspects of the following: why, who, what, where, when, how, how much, what after? There are couple of process of evaluate event oriented decision making system. We will analyze these techniques for MAD and MPE:

a) MAD (mean absolute deviation): It is a decision making forecasting technique which uses the sum of absolute values of errors. The mean absolute deviation measures forecast accuracy by averaging the magnitude of the forecasting errors. It provides minimum deviation regardless of direction.

b) MPE (mean percentage error): MPE is used to determine whether a forecasting method is biased (consistently forecasting high or low). If the forecasting approach is unbiased, the MPE will produce a number that is close to zero. If the result is a large negative percentage, the forecasting method is consistently overestimating. If the result is a significantly negative percentage, the forecasting method is consistently overestimating.

c) SE (standard error of the estimate): It measures the amount by which the actual $Y$ values differ from the estimated, or forecasted $\left(\widehat{Y}_{t}\right)$ values for simple regression (single variable, $Y$ ) and number of observations (n). The mean absolute deviation (MDA) describes the variability of sample between individual members; the standard error of the estimate (SE) describes the uncertainty of how the sample mean represents the population mean (Table 1). We will consider the following notations for calculating forecasting techniques:

$\mathrm{Y}_{\mathrm{t}}=$ the value of a time series at period $\mathrm{t}$ (the actual value in period $\mathrm{t}$ )

$\widehat{\widehat{Y}}_{t}=$ the forecast value for time period $\mathrm{t}$

$\mathrm{e}_{\mathrm{t}}=\mathrm{Y}_{\mathrm{t}}-\widehat{Y}_{t}=$ the forecast error in time period $\mathrm{t}$

$M A D=\frac{1}{n} \sum_{t=1}^{n}\left|Y_{t}-\widehat{Y}_{t}\right|=\frac{1}{n} \sum_{t}^{n}\left|e_{t}\right|$

$M A D==36 / 8=4.5$

$M P E=\frac{1}{n} \sum_{t=1}^{n} \frac{\left(Y_{t}-\widehat{Y}_{t}\right)}{Y_{t}}=\frac{1}{n} \sum_{t=1}^{n} \frac{\left(e_{t}\right)}{Y_{t}}$

$M P E=0.187 / 8=.0234=2.34 \%$

$S E=\sqrt{\sum_{t=1}^{n} \frac{\left(Y_{t}-\widehat{Y_{t}}\right)^{2}}{n-2}}=\sqrt{\sum_{t=1}^{n} \frac{\left(e_{t}\right)^{2}}{n-2}}$

$S E=\sqrt{ } 220 /(8-2)=6.05$.

The MAD indicates that the quality control manager of a factory can make an economic decision for a weekly forecast of production defects (aluminum ingots) on favour of top management of the company and each forecast deviated by an average of 4.5 sizes, standard error of the estimate 6.05 and the MPE of $2.34 \%$ (very small) indicates that the technique is not biased. MPE, SE and MAD are very small and it is an indication of an economic decision for selection of right set of data model.

\section{Risk oriented}

Project feasibility decision depends on sensitivity index (SI) analysis and expected utility (EU) theories. Identification of risks with potential impacts will correlate among uncertainties of a decision. It is a quantitative analysis of negative and positive impacts (PMBOOK, 2013). Sensitivity analysis helps to determine which risks have the most potential impact on the project. It examines the extent to which the uncertainty of each project element affects the objective being examined when all other uncertain elements are held at their baseline values. One typical display of sensitivity analysis is the tornado diagram, which is useful for comparing relative importance and impact of variables that have a high degree of uncertainty to those that are more stable.

a) Sensitivity in product development: It is a process of strategy, organization and concept generation of a new 
Table 1. Product Data forecasting error for a daily number of customers requiring aluminum ingots in a gas station by MAD and MPE.

\begin{tabular}{|c|c|c|c|c|c|c|}
\hline Time (months) & Product batch size $\left(\mathrm{Y}_{\mathrm{t}}\right)$ & Forecast $\left(\widehat{Y_{t}}\right)$ & Error $=\mathbf{e}_{\mathrm{t}}=\left(\mathbf{Y}_{\mathrm{t}}-\widehat{\widehat{Y_{t}}}\right)$ & $\left|\mathbf{e}_{\mathbf{t}}\right|$ & $\left(e_{t}\right)^{2}$ & $\mathbf{e}_{\mathrm{t}} / \mathbf{Y}_{\mathrm{t}}$ \\
\hline 1 & 58 & - & - & - & & - \\
\hline 2 & 54 & 58 & -4 & 4 & 16 & -.074 \\
\hline 3 & 60 & 54 & 6 & 6 & 36 & 0.1 \\
\hline 4 & 55 & 60 & -5 & 5 & 25 & -.091 \\
\hline 5 & 62 & 55 & 7 & 7 & 49 & 0.113 \\
\hline 6 & 62 & 62 & 0 & 0 & 0 & 0 \\
\hline 7 & 65 & 62 & 3 & 3 & 9 & 0.046 \\
\hline 8 & 63 & 65 & -2 & 2 & 4 & -.032 \\
\hline 9 & 72 & 63 & 9 & 9 & 81 & 0.125 \\
\hline Totals & & & 14 & 36 & 220 & 0.187 \\
\hline
\end{tabular}

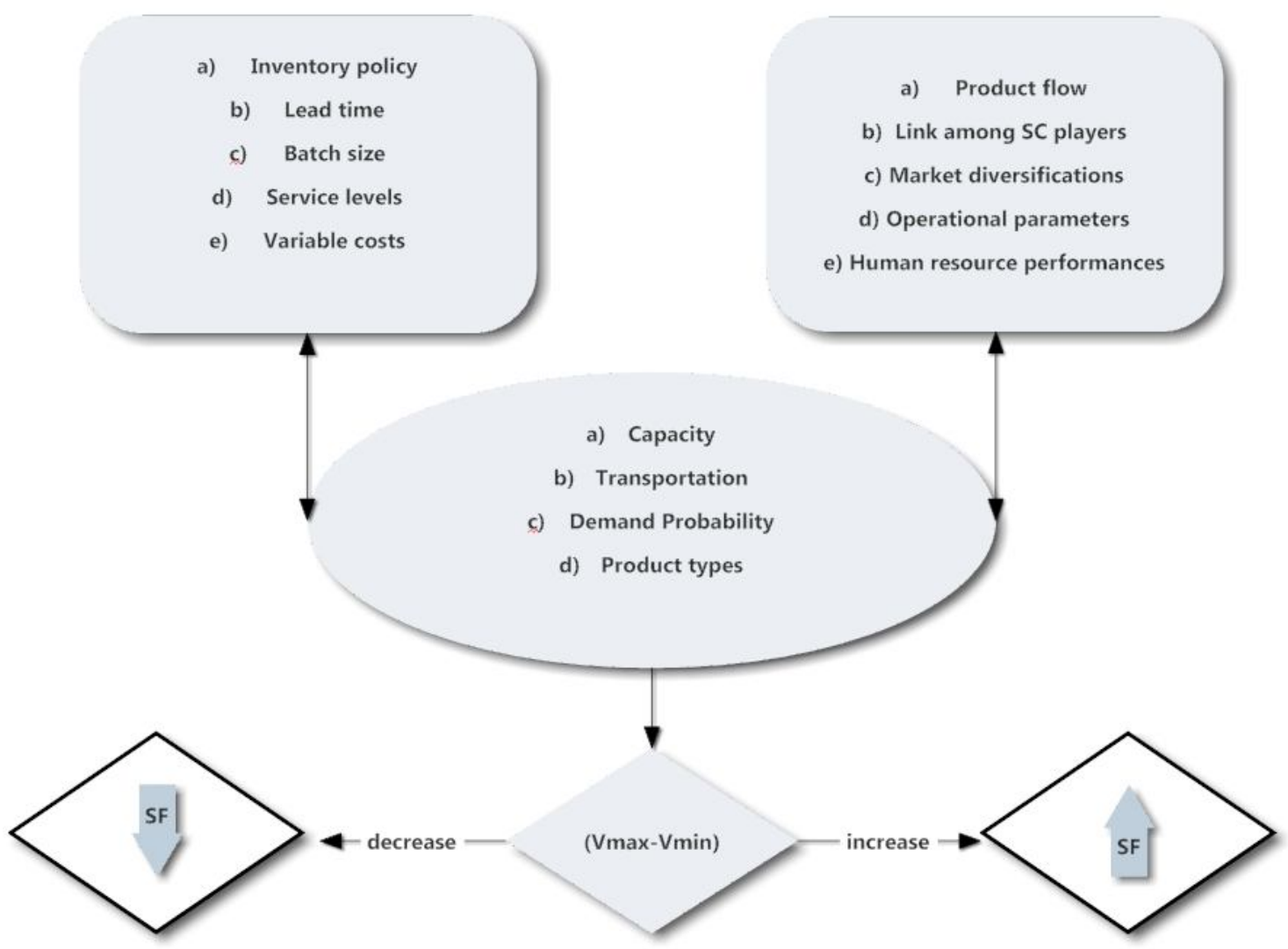

Figure 1. (Vmax-Vmin) Vs. Total SF with Product Management.

product. A way of strategic analysis in product development is the history of the successful company and it means that both the competitive and business strategies i.e. individual weight of each flexibility, and players' performances, have aligned goals as presented in Figure 1. Appropriate sourcing decisions raise business profits by assigning supply chain functions at the right time to the right party, who brings higher economies of scale or a higher level of aggregation of uncertainty. Pricing can be used to attract the target customer segment. Differential pricing can be used to attract customers who value responsiveness as well as customers who want efficiency. The business strategy and supply chain flexibility can then be designed to provide responsiveness to potential customers while improving overall efficiency. Use of resources, the expected output, flexibility of the system and interrelationship among factors play a major role to measure 
performances of a supply chain (The Wall Street Journal, 1997). Maximum and minimum volume has a significant impact on product flexibility. The total flexibility is evaluated while the maximum and minimum volume are changed simultaneously to explore the sensitivity to these performance parameters resulting in an increase in the difference between maximum and minimum volume which implies a decrease in the value of total product flexibility, as shown in

Figure. The total flexibility is increased by volume flexibility, and no other flexibility improvements are needed. However, an additional volume is required to minimize $\left(\mathrm{V}_{\max }-\mathrm{V}_{\min }\right)$ the difference between $\mathrm{V}_{\max }$ and $V_{\min }$ and improving the inventory level to ensure better customer service with a higher flexibility performance parameter. Sensitivity analysis depends on i) Understanding the customer and business uncertainty: the player has to understand the customer needs for each targeted segment and the uncertainty these needs impose on the supply chain. ii) Understanding the business capabilities: the player has to understand what its product chain is designed to do well. iii) Matching strategic fit as presented in Figure 1. To restructure the supply chain for supporting the competitive strategy: Product identification from the supplier allows customers to assume the supplier will meet product quality and service requirements. This can either be companies designed and administered, or they can be internationally recognized using standard programs like the ISO 9000 / ISO 14000 series of certification (Jayaram et al., 1999). b) Inventory uncertainties define all raw materials, work in process, and finished goods within a product chain. It is a major source of cost in a supply chain and has a huge impact on responsiveness (Rossetti and Choi, 2005).

b) $\mathrm{SI}$ in product inventory: It is process of marketing plan creation, evaluation and commercialization of a new product. The average amount of inventory carried should be measured in units, days of demand and financial value. ii) Seasonal inventory- the amount of both cycle and safety inventory that is purchased solely due to seasonal changes in demand. c) Fill rate (order/case)-the fraction of order/demand that was met on time from inventory. It should not be averaged over time but over a specified number of units of demand (that is, every thousand, million etc). This means that an inventory turnover leads to a decrease in average inventory levels and increase in annual sales (Siguaw et al., 1998).
The highest inventory turnover ratio has a high level of liquidity; smaller risk of obsolescence and reduced investment in industry. On the other hand, low inventory level increases the risk of lost sales. Loss of sales results in money in the product competitor's account, thereby improving cash flow, and it leads to a hedge factor, that is, to carry more items and more product inventories than is necessary; further factor, that is, an overestimating sales forecast with inadequate market research and intelligence (John and Dean, 2008). The fundamental trade-off that financial institutions project managers face when making product chain decisions includes the cost of the number, location, capacity, the type of efficiency/net income, the level of responsiveness and the facilities provided to the customers. The trade-off defined in the product inventory driver is between the responsiveness that results from more inventories and the efficiency that results from fewer inventories. Overall trade-off decisions should be made with the objective of increasing total profits. This indicates an understanding of the cost of the structure for performing a product chain activity and the value this brings to the business decision. Strategies such as everyday low pricing and increasing the number of items may foster stable demand that allows for efficiency in the product cycle. Differential pricing can be used to attract customers with varying needs, as long as the strategy helps either to increase market shares and revenues or shrink costs.

c) Expected utility theory: It is a technique about how to make optimal decision under risk and uncertainty. It has a normative interpretation which economists particularly used to think applies in all situations to rational outcomes. The expected utility of an entity is derived from the expected utility hypothesis. This hypothesis derives that under uncertainty, the weighted average of all possible levels of utility will best represent the utility at any given point in time (Lambek, 2007).

Opportunities and threats are calculated by EMV (Expected Monetary Values). It has a risk neutral region to approach or get back of an economic feasibility. The EMV of opportunities will generally be expressed as positive values, while those of threats will be negative. EMV requires a risk neutral assumption, neither risk averse, nor risk seeking. EMV for a project is calculated by multiplying the value of each possible outcome by its probability of occurrence and adding the products together.

\section{CALCULATIONS}

\section{Sensitivity index}


Sensitivity index $(\mathrm{SI})$ is a number calculated by a defined procedure which gives information about the relative sensitivity of results to different parameters of a product development model. A simple example of a sensitivity index is the elasticity of a variable with respect to a parameter (Table 2). The higher the elasticity, the higher the sensitivity of results

Farok and Homayouni 29

to changes in that parameter:

$S I=\left(D_{\max }-D_{\min }\right) / D_{\max }$

Where $D_{\max }$ is the output result when the parameter in question is set at its maximum value and $D_{\min }$ is the result for the minimum parameter value. It is useful for product market sensitivity analysis between two products of a financial institution (FI).

In cases where comparisons between different models are not important, the following even simpler sensitivity index can be perfectly adequate (and perhaps even preferable).

$S I=\left(D_{\max }-D_{\min }\right)$

Actually, a number of complex indices for use in situations where the modeller wishes to assess the sensitivity of several output variables simultaneously. It is useful for cases where the result of interest is a ranking of several variables with similar product of a manufacturing industry (Nagele, 2003). (Table 3)

Table 2. Product diversification with investment decisions.

\begin{tabular}{|c|c|c|c|c|c|}
\hline $\begin{array}{ll}\text { Products } & \text { Market } \\
\text { Diversifications (Interest) }\end{array}$ & $\begin{array}{l}D_{\max } \\
(\%)\end{array}$ & $\begin{array}{l}D_{\min } \\
(\%)\end{array}$ & $S I=\left(D_{\max }-D_{\min }\right) / D_{\max }$ & $\begin{array}{l}\text { Product } \\
\text { strategy }\end{array}$ & Investment decisions \\
\hline $\begin{array}{l}\text { Mortgage loan A (July } 2017 \text { to } \\
\text { January 2017) }\end{array}$ & 3.00 & 2.50 & 0.1667 & More sensitive & \multirow{2}{*}{$\begin{array}{l}\text { FI should accept the Supply } \\
\text { Flexibility (SF) for products to } \\
\text { invest more in mortgages. }\end{array}$} \\
\hline $\begin{array}{l}\text { Credit line loan (July } 2017 \text { to } \\
\text { January 2017) }\end{array}$ & 3.5 & 3.25 & 0.0714 & Less sensitive & \\
\hline
\end{tabular}

Table 3. SI and management decision.

\begin{tabular}{|c|c|c|c|c|c|}
\hline $\begin{array}{l}\text { Batch size } \\
\text { diversifications }\end{array}$ & $D_{\max }(\mathrm{mm})$ & $D_{\min }(\mathrm{mm})$ & $\begin{array}{c}S I=\left(D_{\max }-D_{\min }\right) \\
(\mathrm{mm})\end{array}$ & Ranking strategy & Management decisions \\
\hline SS sheet & 5.25 & 4.25 & 1.00 & $2^{\text {nd }}$ & \multirow{3}{*}{$\begin{array}{l}\text { Design cost and service levels of } \\
\mathrm{Cl} \text { sheet should get preference. }\end{array}$} \\
\hline $\mathrm{DCl}$ sheet & 7.50 & 6.75 & 0.75 & $3^{\text {rd }}$ & \\
\hline $\mathrm{Cl}$ sheet & 8.75 & 7.00 & 1.75 & $1^{\text {st }}$ & \\
\hline
\end{tabular}

\section{Expected utility}

Expected utility $(E U)$ is a measurement for economic concept of viability of risks under uncertainty.

Expected Utilities, EU $=\sum_{t=1}^{n}\left(\mathrm{u}\left(\mathrm{a}_{\mathrm{t}}\right) \cdot \mathrm{P}\left(\mathrm{a}_{\mathrm{t}}\right)\right.$

For Project 1: Total Utilities, $E U=1 / 3 \times 1+2 / 3 \times 3=2.33$

For Project 2: Total Utilities, EU $=1 / 3 \times 2+2 / 3 \times 2=2$

Management Decision: Project 1 will get preference. (Table 4)

Table 4. Applications of game theory.

\begin{tabular}{llcc}
\hline & No. of operations & Schedule on time Pr(1/3) & Schedule on budget Pr(2/3) \\
\hline \multirow{2}{*}{ Project Managers Possible actions } & Possibilities of Project 1 & 1 & 3 \\
& Possibilities of Project 2 & 2 & 2 \\
\hline
\end{tabular}


Expected Utilities of Hypothesis: Two projects have same probability on budget and on schedule on contract. Considering monetary perspectives: i) project- 1 has $40 \%$ chance for payment on contract period $\$ 2500$ and $60 \%$ of chance for planning cost on budget $\$ 1600$, ii) project-2 has $25 \%$ chance for payment on contract period of $\$ 5000$ and

Afr J Eng Res

$75 \%$ of chance for planning cost on budget $\$ 1000$.

Which project will be more compatible for management decision?

Solution: We have two components time and budget:

Total Utilities, EU $=\operatorname{Per}(\mathrm{t}) \cdot r_{t}^{0.5}+\operatorname{Per}(\mathrm{b}) r_{b}^{0.5}$

For project 1: Expected monetary values $=0.4 \times 2500+0.6 \times 1600=\$ 1960$

Total Utilities $(\mathrm{EU})=0.4 \times 2500_{\text {time }}^{0.5}+0.6 \times 1600_{\text {budget }}^{0.5}=44$

For Project 2: Expected Monetary values $=0.25 \times 5000+0.75 \times 1000=\$ 2000$.

Total Utilities $(\mathrm{EU})=0.25 \times 5000_{\text {time }}^{0.5}+0.75 \times 1000_{\text {budget }}^{0.5}=41.4$

Management Decision: Project 2 is more compatible considering monetary values and Project 1 is more feasible with respect to utilities.

\section{Data analysis}

Now a day organizations must develop forecasts to make timely decisions in the face of uncertainty. Forecasts must be accurate enough to be useful. Event oriented data can be auto correlated, but the data cannot under away from the mean for any extended period of time. Usually, we can use the available historical data to estimate the mean value of the series as the forecast for future periods. The most sophisticated technique is to get the estimated mean and revert to the mean for additional future periods. Forecast decision can be updated when new information becomes available, so updating provides some degree of responsiveness to a potential change in the underlying level of the data. Project evaluation data depends on communication management due to time and budget.

\section{SIMULATIONS}

The purpose of the forecasting process is to improve the efficiency of the business and that implies maximizing the bottom line profit. Mathematics shows many faces as it works in these diverse settings. It measures the quality of information and finds the best alternative. It quantifies and manages uncertainty and automates decision making. Modeling and computation build the mathematical abstraction of reality 'upon' which these and many other powerful mathematical tools operate. Mathematics is indeed the foundation of modern decision making. This research limits the possibilities of drawing recommendations but it is very descriptive by nature. It consists of an initial literature research and a model to explain product management. This project is focused on internal functional area responsibilities for product management performance and developed a model to examine the possible contribution of cost benefit analysis i.e. industrial to information society, national to world economy, short to long term thinking, centralization to decentralization etc. Product development and inventory responsiveness are important for schedule fluctuations, purchasing in time, slack capacity, demand volatility, mean demand, accurate volume and market forecast. Expected outcomes can be achieved when sound risk management is used to capture opportunities and reduce threats (Cooper et al., 2014). In the practical sense, the challenge is to find suitable mathematical model for a standard organization as the organizations are large and complex systems.

\section{DISCUSSION}

This model explains the ability of a product development as well as inventory system to adapt to various uncertainties. Forecasting accuracy is a critical factor for reducing project costs and providing better customer service (Makridakis and Hibon 2000). The relationship includes dimensions of product chain flexibility and examines their relationships with business uncertainty, project monetary policies, overall performances and functional strategies. It considers a number of technological attributes, that is, the efficiency of processing an operation, the number of different flexibilities with individual parametric weights, and the probability of choosing a chain to alternate options presented in this model. The role of flexibility has found the right balance between responsiveness and efficiency. Each flexibility affects business strategy. Having more flexibility generally makes a product chain more responsive, while having fewer, central flexibilities creates higher efficiency. Holding higher levels of product inventory increases the responsiveness of a chain, while keeping inventory low increases the chain's efficiency. Using faster modes of transportation increases a chain's responsiveness, while using slower modes generally increases efficiency. Sensitivity index can vastly improve the product chain performance on both dimensions.

\section{CONCLUSIONS}


The increase in globalization of the business in the performance of product availability has made it more difficult to execute business strategies. Increasing component variety, decreasing component life cycle, and demanding customers with global competition make business strategies more difficult, as these factors can motivate decision performance. On the other hand,

increasing the number of facilities and decreasing the response time, uncertainty and transportation cost leads to a higher inventory and facility cost. Probability has more impact on economic decision making element: customer demand can never be forecasted exactly; travel times will never be certain; and machines and vehicles will break down at any time.

i) The concept of uncertainty is an application of the product chain. A true flexible buyer-supplier relationship can be obtained when a collaborative relationship exists in which information is shared continuously. The benefits of this strong collaboration are not only cost-effective but also go beyond a translated larger flexibility in the buyersupplier relationship. We obtained MPE, MAD, SE, SI and EU for selection of product batch size with respect to delivery, logistic, market, mix, operation, organization and volume forecast efficiencies respectively.

ii) The modeling of product flexibility and its impacts on multiple entity flows are important for the level of flexibility to attain a given lead time performance and for the designers and managers of flexible product chain systems to arrive at an economic class. It is important to examine the significance of the product chain position in integrating values of supplier, manufacturer and market in a supply network. So, modeling of economic decision flexibility is a crucial need for every aspect as a mechanism to maintain a competitive position in domestic markets as well as global strategies.

iii) EU is a management decision making model. Performance of the product chain can significantly improve if the entire chain is designed with project components. It is easy to recognize the importance of stakeholders by increasing the competitiveness to satisfy the customer demand with less cost and shorter time.

iv) This model is a benchmark set of product chain instances and it would improve the modeling and analysis being performed by the academician, researcher and practitioner of supply chain communities in providing thresholds for the comparison of different models, methodologies and applications.

v) Communication networking is an important factor for perfect decision making. Number of communications link, probability and weight of project component has significant impacts on product SF. This model can help entrepreneurs evaluate the responsiveness and attractiveness of their product to customer demand, which can define cumulative output in a global market.

\section{RECOMMENDATIONS}

This effort is a proof of concept study, and in many situations we may never know the networks product chain because of their dynamic nature and lack of information. Supplier qualification and training, resources and information sharing have significant implications for

$$
\text { Farok and Homayouni }
$$

product management policies in any firm, but particularly at different stages of maturity with networking. Further research has to provide evidence on the specific factors that determine flexibility as described in the literature review. It has to be determined how flexibility deals with external market disruptions and meets demand volatility with the aspects of a longer term and strategic perspective. Uncertainty is implemented in order to develop competitiveness in a changing environment.

i) MAD, SE and MPE should incorporate suppliers' data and channel members into product management analysis and measurement of the model of product chain system.

ii) SI and EU should address how companies with feasible project policies can use alternate models of demand with multi-channel strategy.

iii) It should consider how flexibility counters uncertainties in the product develop element and the impact of disruptions for supply shortages on the market valuation.

iv) Concurrent product and process design with regard to flexibility requirements is an important research area. It is expected that through these expositions of theoretical and experimental solutions to project analysis, this model will contribute in estimate the total performance criteria to provide a critical solution to the problem of flexibility in multi-national business firms.

v) Future research work should incorporate the relationship between data analysis, product flexibility and overall firm performance in a variety of product settings to confirm an economic decision.

\section{REFERENCES}

Cooper D, Bosnich P, Grey S, Purdy G, Raymond G, Walker P, Wood $M, 2014$. Project Risk Management Guidelines: Managing Risk with ISO 31000 and IEC 62198, $2^{\text {nd }}$ Edition.

Jayaram J, Drooze C, Vickery SK, 1999. The impact of human resource management practices on manufacturing performance. Journal of Operations Management, 18(1): 1-20.

John $H$, Dean W, 2008. Business Forecasting. $9^{\text {th }}$ Edition. Pearson Publisher, USA.

Lambek J, 2007. Foundations of mathematics. Encyc. Britannica.

Makridakis S, Hibon M, 2000. The M3-Competition: results, conclusions and implications. Int J Forecast, 16(4): 451-476.

Mendenhall W, Sincich T, 2012. A Second Course in Statistics, Regression Analysis, $7^{\text {th }}$ Edition. University of Florida, USA.

Nagele $P, 2003$. Misuse of standard error of the mean (SEM) when reporting variability of a sample. A critical evaluation of four anaesthesia journals. Brit J Anaesthesia, 90(4): 514-516.

PMBOOK, 2013. $5^{\text {th }}$ Edition, Project Management Institute (PMI), USA.

Rossetti C, Choi TY, 2005. On the dark side of strategic sourcing experiences from the aerospace industry. Academy of Management Exec, 19(1): 46-60. 
Siguaw JA, Simpson PM, Baker TL, 1998. Effects of supplier market orientation on distributor market orientation and the channel relationship: The distributor perspective. J Market, 62: 99-111.

The Wall Street Journal, October 23, 1997.

Citation: Farok G, Homayouni S, 2018. Foundations of mathematics

play the baseline for data exploring, forecasting and analyzing of risks to get an economic decision. Afr J Eng Res, 6(2): 25-31. 